\title{
Lapatinib Inhibits Amphiregulin-induced BeWo Choriocarcinoma Cell Proliferation by Reducing ERK1/2 and AKT Signaling Pathways
}

\author{
LETICIA VICOSA PIRES ${ }^{1,2}$, YUYIN YI ${ }^{2}$, JUNG-CHIEN CHENG ${ }^{2}$, LOLITA SCHNEIDER PIZZOLATO ${ }^{3}$, \\ ELVIRA CORDERO ${ }^{3}$, PETER C. K. LEUNG ${ }^{2}$ and ILMA SIMONI BRUM ${ }^{1,3}$ \\ ${ }^{1}$ Department of Gynaecology and Obstetrics, Porto Alegre Clinical Hospital, Porto Alegre, RS, Brazil; \\ ${ }^{2}$ Department of Obstetrics and Gynaecology, BC Children's Hospital Research Institute, \\ University of British Columbia, Vancouver, BC, Canada; \\ ${ }^{3}$ Department of Physiology, Basic Health Science Institute, \\ Federal University of Rio Grande do Sul, Porto Alegre, RS, Brazil
}

\begin{abstract}
Background: Human choriocarcinoma is the most aggressive type of gestational trophoblastic neoplasia. The expression of epidermal growth factor receptor (EGFR) in choriocarcinomas is significantly higher than those of trophoblastic cells in healthy placentas. Lapatinib is a potent EGFR and human epidermal growth factor receptor 2 (HER2) inhibitor that inhibits cell proliferation and induces apoptosis in various human cancer cells. Amphiregulin (AREG) is the most abundant EGFR ligand in amniotic fluid during human pregnancy. Aim: To explore the role of AREG in human choriocarcinoma cell proliferation. Materials and Methods: The effect of lapatinib and AREG on cell proliferation was examined by the MTT assay. Western blots were used to investigate EGFR and HER2 expression, and the activation of caspase-3, extracellular signal-regulated kinases $1 / 2$ (ERK1/2) and phosphatidylinositol 3-kinase /protein kinase B (PI3K/AKT) signaling pathways. Results: Treatment with lapatinib reduced BeWo cell proliferation by inducing apoptosis. Moreover, AREG treatment stimulated BeWo cell proliferation by activating ERK1/2 and PI3K/AKT signaling pathways, which was blocked by lapatinib. Conclusion: Targeting EGFR/HER2 might be a useful therapeutic strategy for human choriocarcinoma.
\end{abstract}

The placenta is an important organ required for the successful development of the fetus during pregnancy.

Correspondence to: Peter C.K. Leung, Ph.D., FCAHS, FRSC, Department of Obstetrics and Gynaecology, BC Children's Hospital Research Institute, University of British Columbia, Room 317, 950 west 28th Ave., Vancouver, British Columbia V5Z 4H4, Canada. Tel: +1 6048752718, Fax: +1 6048752717, e-mail: peter.leung@ubc.ca

Key Words: Lapatinib, EGFR, HER2, choriocarcinoma.
Gestational trophoblastic disease is a group of rare diseases in which placental trophoblast cells grow abnormally inside the uterus after conception. Based on the histological and pathological characteristics, these can be broadly divided into two groups: i) Benign trophoblastic lesions that include hydatidiform moles (partial and complete); and ii) gestational trophoblastic neoplasia (GTN) (1-3). GTNs are uncommon malignancies which encompass a group of interrelated, but distinct tumors that include invasive hydatidiform mole, placental-site trophoblastic tumor, epithelioid trophoblastic tumor and choriocarcinoma $(4,5)$.

Although human choriocarcinoma is the most aggressive type of GTN, with abnormal invasive, migratory and proliferative properties, it is among the few types of human cancer that are highly responsive to chemotherapy and, unlike other types of malignant tumors, metastatic choriocarcinomas are potentially curable by combined chemotherapy and adjuvant surgical procedures $(6,7)$. However, in a small but significant proportion of patients, the disease exhibits resistance to traditional chemotherapy and patients fail to survive due to delayed diagnosis or a recurrent tumor (8-10). Therefore, it is important and necessary to develop new therapies or strategies for treating or preventing choriocarcinomas (11).

The Erb-b2 receptor tyrosine kinases (ERBB) receptor tyrosine kinase (RTK) family comprises four members: Epidermal growth factor receptor (EGFR; ERBB1), HER2 (ERBB2), HER3 (ERBB3) and HER4 (ERBB4). The expression level of EGFR in choriocarcinomas is significantly higher than that of trophoblastic cells in healthy placentas, whereas the expression levels of ERBB3 and ERBB4 do not vary significantly (12). In addition, the HER2 expression level in hydatidiform mole is increased with malignant transformation $(13,14)$. EGF, amphiregulin (AREG) and transforming growth factor $\alpha$ (TGF $\alpha$ ) bind 
specifically to EGFR $(15,16)$. Among these EGFR ligands, AREG is primarily expressed in human placenta throughout pregnancy and is thought to be the key molecule involved in the regulation of placental development and maturation. Importantly, the expression level of AREG is significantly higher than that of EGF and TGF $\alpha$ in human choriocarcinoma cells (17). Together, these results suggest that AREG/EGFR signaling may play important roles in the development and progression of human choriocarcinomas.

Despite having no direct identified ligand, HER2 can be activated via dimerization with other ligand-bound ERBB receptors and this heterodimerization can further potentiate signaling that is mediated by those ligand-bound ERBB receptors $(18,19)$. Using drugs that target EGFR or HER2 has emerged as effective treatments against various types of human cancers. However, to the best of our knowledge, the role of EGFR-mediated signaling in the regulation of human choriocarcinoma progression remains unclear. Lapatinib is a potent inhibitor of EGFR and HER2 tyrosine kinase catalytic activity. It has been shown that treatment with lapatinib inhibits proliferation and induces apoptosis of different types of human cancer cells (20). Given the high expression levels of AREG and EGFR in choriocarcinoma, the present study examined the effect of lapatinib on cell apoptosis and on AREG-induced cell proliferation in two human choriocarcinoma cell lines.

\section{Materials and Methods}

Antibodies and reagents. The polyclonal anti-EGFR $(1: 1,000)$ and monoclonal anti- $\alpha$-tubulin $(1: 5,000)$ antibodies were obtained from Santa Cruz Biotechnology (Santa Cruz, CA, USA). The monoclonal anti-HER2 (1:2,000), anti-phospho-ERK1/2 (Thr202/Tyr204) $(1: 1,000)$ and polyclonal anti-caspase-3 $(1: 1,000)$, anti-ERK1/2 $(1: 1,000)$, anti-phospho-AKT (Ser473) $(1: 1,000)$ and anti-AKT $(1: 1,000)$ antibodies were obtained from Cell Signaling Technology (Danvers, MA, USA). Horseradish peroxidase-conjugated goat antimouse and goat anti-rabbit $\mathrm{IgG}$ were obtained from Bio-Rad Laboratories (Hercules, CA, USA). Lapatinib was purchased from Selleckchem (Houston, TX, USA). PI3K inhibitor LY294002 was obtained from Sigma (St. Louis, MO, USA). Mitogen-activated protein kinase kinase enzymes (MEK) inhibitor U0126 was obtained from Calbiochem (San Diego, CA, USA). Recombinant human AREG was purchased from R\&D Systems (Minneapolis, MN, USA). Lapatinib, LY294002, and U0126 solutions were prepared in dimethyl sulfoxide (DMSO; Sigma), and AREG was prepared in phosphate buffer solution. Equal volumes of vehicle control were loaded in all treatment groups.

Cell culture. The human choriocarcinoma cell lines BeWo and JEG3 were obtained from the American Type Culture Collection (Manassas, VA, USA). Cells were grown in a 1:1 (v/v) mixture of Dulbecco's modified Eagle medium/nutrient mixture F-12 (DMEM/F12) medium (Gibco, Life Technologies, Burlington, ON, Canada) supplemented with $10 \%$ fetal bovine serum (FBS; Hyclone Laboratories Inc., Logan, UT, USA). Cultures were maintained at $37^{\circ} \mathrm{C}$ in a humidified atmosphere of $5 \% \mathrm{CO}_{2}$ in air.

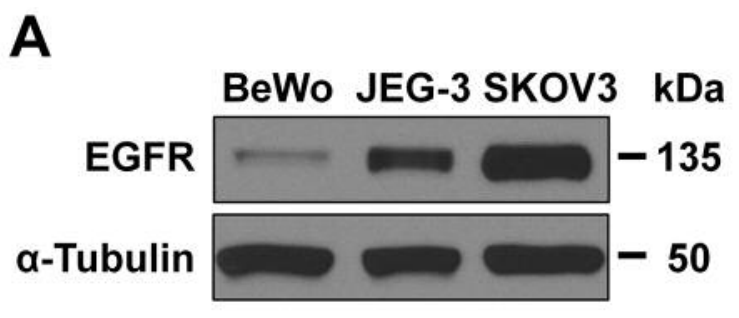

B

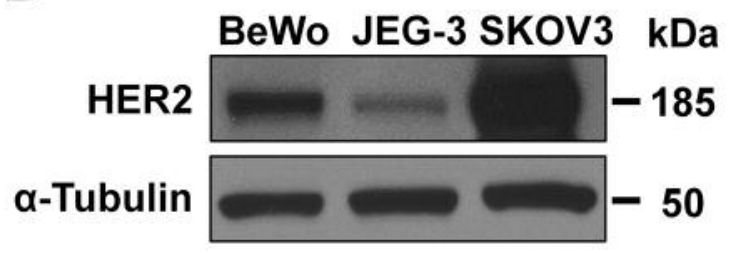

Figure 1. The expression levels of epidermal growth factor receptor (EGFR) and human epidermal growth factor receptor 2 (HER2) in BeWo and JEG-3 cells. A: Endogenous levels of EGFR were examined in BeWo and JEG-3 cells by western blot. B: Endogenous levels of HER2 were examined in BeWo and JEG-3 cells by western blot. The ovarian cancer cell line SKOV3 was used as a positive control.

3-(4,5-Dimethylthiazol-2-yl)-2,5-diphenyltetrazolium bromide (MTT) assay. Cells were seeded in a 24 -well plate $\left(2 \times 10^{4} /\right.$ well $)$ with $500 \mu \mathrm{l}$ of medium and treated with different concentrations ( 1 and $10 \mu \mathrm{M}$ ) of lapatinib every $24 \mathrm{~h}$ for $96 \mathrm{~h}$. In different experiments, cells treated with $20 \mathrm{ng} / \mathrm{ml}$ recombinant AREG every $24 \mathrm{~h}$ for $96 \mathrm{~h}$. Effects of different compounds were also examined by pre-treating the cells with LY294002 $(10 \mu \mathrm{M})$, U0126 $(10 \mu \mathrm{M})$ or lapatinib ( 1 or $5 \mu \mathrm{M}$ ) for $1 \mathrm{~h}$ prior to treatment with $20 \mathrm{ng} / \mathrm{ml}$ AREG every $24 \mathrm{~h}$ for $96 \mathrm{~h}$. At least three independent experiments were performed. 3-(4,5-Dimethylthiazol-2-yl)-2,5-diphenyltetrazolium bromide (MTT; Sigma) was added at different time points to a final concentration of $0.5 \mathrm{mg} / \mathrm{ml}$ and cells were then incubated for $4 \mathrm{~h}$. After incubation, the media were removed and DMSO was added to each well to dissolve the crystals. The absorbance values were examined by spectrophotometric microplate reader.

Western blot. The protein levels of EGFR and HER2 in BeWo and JEG-3 cells were examined by western blot. To examine the effect of lapatinib on the protein levels of cleaved caspase-3, cells were treated with $10 \mu \mathrm{M}$ lapatinib for $24 \mathrm{~h}$. To examine the effects of AREG on the phosphorylation of ERK $1 / 2$ and AKT, cells were treated with $20 \mathrm{ng} / \mathrm{ml}$ AREG for $10 \mathrm{~min}, 30 \mathrm{~min}$, or $60 \mathrm{~min}$. The effects of lapatinib was examined by pre-treating the cells with $1 \mu \mathrm{M}$ or $5 \mu \mathrm{M}$ lapatinib for $1 \mathrm{~h}$ prior to treatment with $20 \mathrm{ng} / \mathrm{ml}$ AREG for $60 \mathrm{~min}$. At least three independent experiments were performed.

Briefly, cells were lysed in ice-cold lysis buffer (Cell Signaling Technology) with added protease inhibitor cocktail (Sigma-Aldrich, St Louis, MO, USA). Equal amounts of protein were separated by sodium dodecyl sulfate-polyacrylamide gel electrophoresis and transferred onto polyvinylidene difluoride membranes. After blocking for $1 \mathrm{~h}$ with $5 \%$ non-fat dry milk in Tris-buffered saline (TBS), the membranes were 

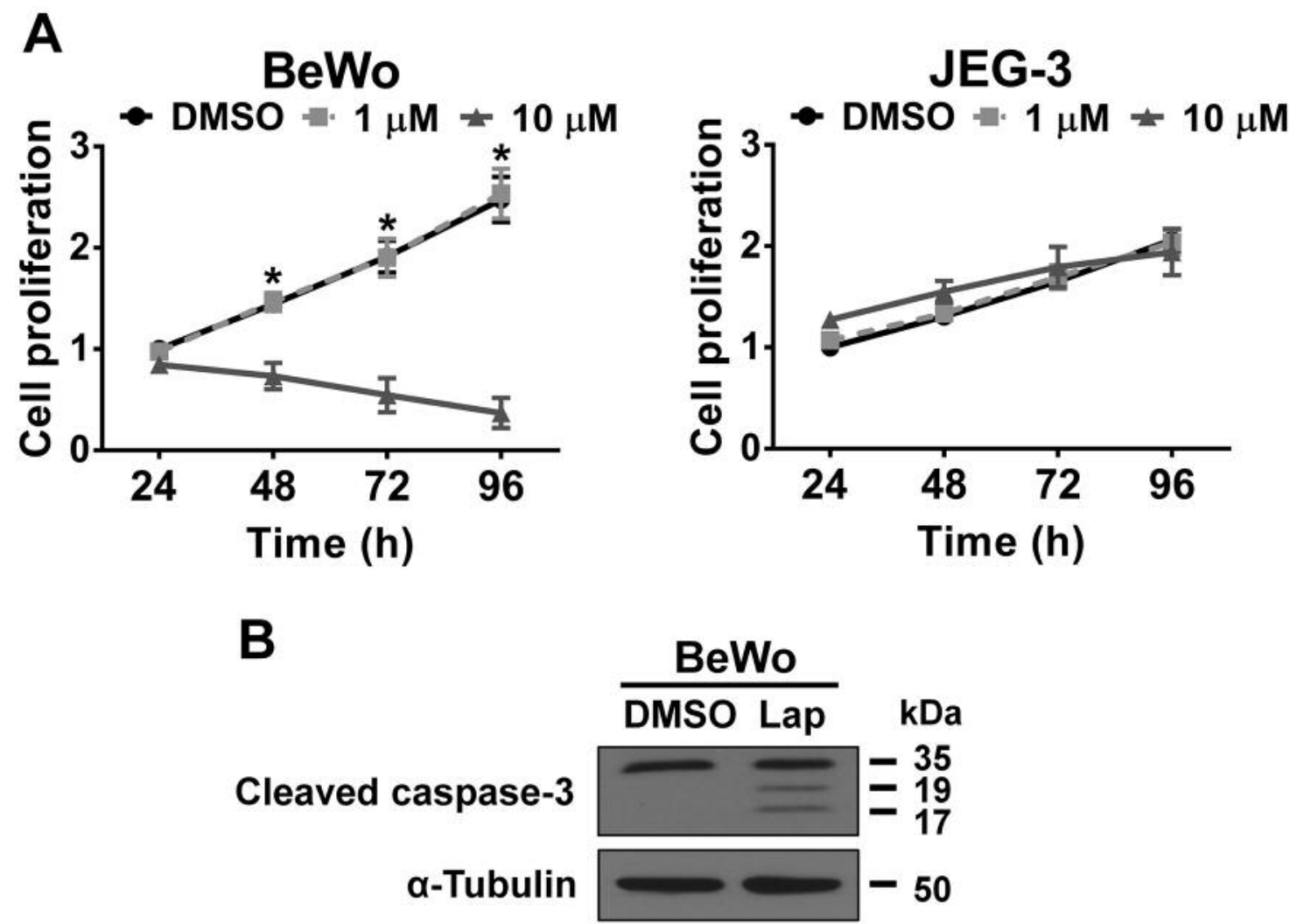

Figure 2. Lapatinib induces cell apoptosis in BeWo cells. A: BeWo and JEG-3 cells were treated with vehicle (dimethyl sulfoxide; DMSO) control, 1 or $10 \mu \mathrm{M}$ lapatinib every $24 \mathrm{~h}$. Cell proliferation was examined by MTT assay. B: BeWo cells were treated with $10 \mu \mathrm{M}$ lapatinib for $24 \mathrm{~h}$. The protein level of cleaved caspases-3 was examined by western blot. Cell proliferation results are presented as the mean \pm SEM of at least three independent experiments. $*$ Significantly different at $p<0.05$ compared with the control.

incubated overnight at $4^{\circ} \mathrm{C}$ with primary antibodies diluted in TBS with $5 \%$ non-fat milk. Following primary antibody incubation, the membranes were incubated for $1 \mathrm{~h}$ with appropriate horseradish peroxidase-conjugated secondary antibody. Immunoreactive bands were detected using enhanced chemiluminescent substrate or Super Signal West Femto chemiluminescent substrate (Pierce, Thermo Fisher Scientific) and X-ray film.

Statistical analysis. Results are presented as the mean \pm SEM of at least three independent experiments performed with different passages of cells. Multiple group comparisons were analyzed by one-way ANOVA followed by Tukey's multiple comparison test using PRISM software (GraphPad Software, San Diego, CA, USA). Differences in means were considered significant at $p<0.05$.

\section{Results}

EGFR and HER2 are expressed in BeWo and JEG-3 cells. To the best of our knowledge, thus far, the expression levels of EGFR and HER2 in human choriocarcinoma cell lines have not been clearly demonstrated. To examine the expression levels of EGFR and HER2, the total protein extracted from two human choriocarcinoma cell lines, BeWo and JEG-3, were analyzed by western blot. A human ovarian cancer cell line, SKOV3, which has been reported to express EGFR and high levels of HER2, was used a positive control $(21,22)$. As shown in Figure 1A, both BeWo and JEG-3 cells expressed EGFR and the protein level of EGFR was higher in JEG-3 cells than that in BeWo cells. Similarly, HER2 protein was detected in both cell lines. Interestingly, BeWo cells expressed a higher level of HER2 when compared with JEG-3 cells (Figure 1B).

Lapatinib inhibits cell proliferation in BeWo, but not in JEG3 cells. To examine the effect of lapatinib on cell proliferation in human choriocarcinoma cells, BeWo and JEG-3 cells were treated with $1 \mu \mathrm{M}$ and $10 \mu \mathrm{M}$ of lapatinib every $24 \mathrm{~h}$ for 96 h. As shown in Figure 2A, treatment with $1 \mu \mathrm{M}$ of lapatinib did not affect proliferation of BeWo cells, while cell proliferation was significantly inhibited by treatment with 10 $\mu \mathrm{M}$ lapatinib for $48 \mathrm{~h}$, with the greatest inhibitory effect being observed after $96 \mathrm{~h}$ of treatment. To our surprise, neither treatment with $1 \mu \mathrm{M}$ nor $10 \mu \mathrm{M}$ of lapatinib affected proliferation of JEG-3 cells. Treatment with $10 \mu \mathrm{M}$ lapatinib 

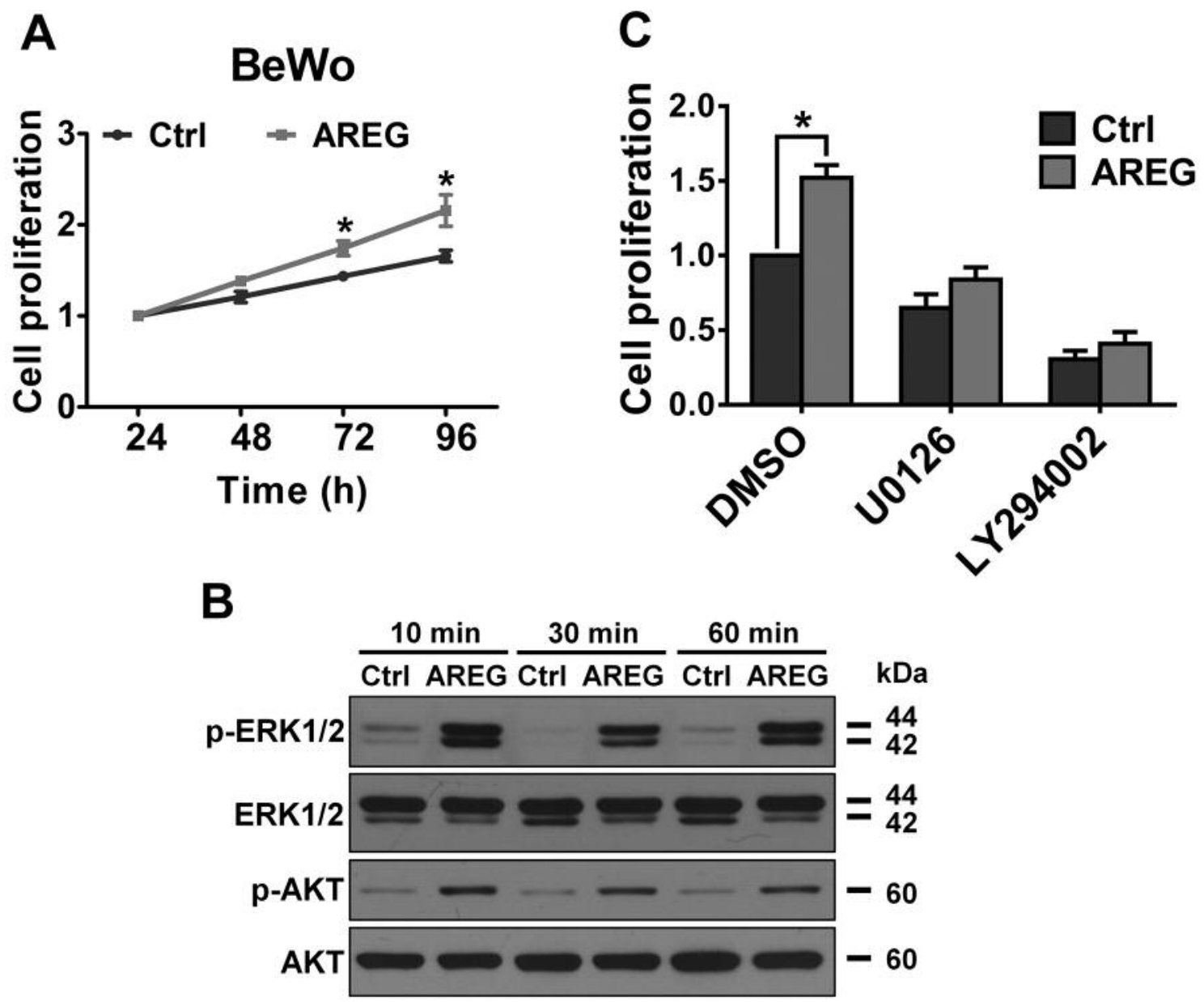

Figure 3. Amphiregulin (AREG) stimulates BeWo cell proliferation and activates extracellular signal-regulated kinases 1/2 (ERK1/2) and phosphatidylinositol 3-kinase/protein kinase B (PI3K/AKT) signaling pathways. A: Cells were treated without or with $20 \mathrm{ng} / \mathrm{ml}$ AREG every $24 \mathrm{~h}$. The cell proliferation was examined by the MTT assay. B: Cells were treated with $20 \mathrm{ng} / \mathrm{ml}$ AREG for the indicated durations. Phosphorylation of ERK1/2 and AKT was determined by western blot using antibodies specific for the phosphorylated forms of ERK1/2 (p-ERK1/2) and AKT (p-AKT). Membranes were stripped and reprobed with antibodies to total ERK1/2 and AKT. C: Cells were pre-treated with mitogen-activated protein kinase kinase enzyme (MEK) inhibitor U0126 (10 $\mu \mathrm{M})$ or PI3K inhibitor LY294002 (10 $\mathrm{\mu M})$ for $1 \mathrm{~h}$ and then treated with $20 \mathrm{ng} / \mathrm{ml}$ AREG every $24 \mathrm{~h}$ for $96 \mathrm{~h}$. Cell proliferation was examined by MTT assay. DMSO: Dimethyl sulfoxide. The cell proliferation results are presented as the mean \pm SEM of at least three independent experiments. *Significantly different at $p<0.05$ compared to the control (Ctrl).

reduced the basal number of BeWo cells, suggesting its proapoptotic effect. To further confirm this, BeWo cells were treated with $10 \mu \mathrm{M}$ lapatinib and the expression level of cleaved caspase-3, an important apoptosis marker, was examined by western blot. As shown in Figure 2B, treatment for $24 \mathrm{~h}$ with $10 \mu \mathrm{M}$ lapatinib significantly induced the expression of cleaved caspase-3. These results agree with a previous study demonstrating the pro-apoptotic effect of lapatinib on other human cancer cells (20).

AREG stimulates cell proliferation by activating ERK1/2 and PI3K/AKT signaling pathways. To date, the effect of AREG on human choriocarcinoma cell proliferation remains unclear. It has been shown that the concentration of AREG in human amniotic fluid can reach $20 \mathrm{ng} / \mathrm{ml}$ (17). Therefore, BeWo cells were treated with $20 \mathrm{ng} / \mathrm{ml}$ AREG and the effect of AREG on cell proliferation was examined by MTT assay. As shown in Figure 3A, cell proliferation significantly increased after $72 \mathrm{~h}$ and $96 \mathrm{~h}$ of AREG treatment. The ERK $1 / 2$ and PI3K/AKT signaling pathways are wellestablished mediators of EGFR. Our results showed that in BeWo cells, treatment with AREG for 10, 30 and $60 \mathrm{~min}$ induced the phosphorylation of ERK1/2 and AKT, indicating the activation of these two pathways (Figure 3B). In addition, inhibition of ERK $1 / 2$ by pre-treating cells with MEK inhibitor U0126 reduced basal cell proliferation and 
abolished AREG-stimulated cell proliferation. Similarly, the basal level of cell proliferation and AREG-stimulated cell proliferation were blocked by pre-treatment with PI3K inhibitor LY294002 (Figure 3C). Together, these results indicate that AREG can stimulate human choriocarcinoma cell proliferation via activating ERK1/2 and PI3K/AKT signaling pathways.

Lapatinib blocks AREG-stimulated cell proliferation by attenuating ERK1/2 and PI3K/AKT signaling pathways. Our results showed that treatment with low concentration $(<10$ $\mu \mathrm{M})$ of lapatinib alone did not induce apoptosis of BeWo cells. Therefore, we examined whether low concentrations $(1 \mu \mathrm{M}$ and $5 \mu \mathrm{M})$ of lapatinib affected AREG-induced activation of ERK1/2 and PI3K/AKT signaling pathways as well as AREGstimulated cell proliferation. As shown in Figure 4A, pretreatment of BeWo cells with $1 \mu \mathrm{M}$ of lapatinib partially attenuated AREG-induced activation of ERK1/2 and PI3K/AKT signaling pathways. The AREG-induced activation of ERK1/2 and PI3K/AKT signaling pathways was totally blocked by pre-treatment with $5 \mu \mathrm{M}$ of lapatinib. MTT assay results further showed that treatment with $1 \mu \mathrm{M}$ or $5 \mu \mathrm{M}$ of lapatinib blocked AREG-stimulated BeWo cell proliferation (Figure 4B).

\section{Discussion}

Lapatinib has been shown to inhibit cell proliferation and induce cell apoptosis of different types of human cancer cells. However, its effects on human choriocarcinoma cells remain unknown. The present study, for the first time, showed that treatment with lapatinib alone reduced cell proliferation by inducing apoptosis of BeWo cells. In addition, we demonstrated that AREG stimulated BeWo cell proliferation by activating ERK1/2 and PI3K/AKT signaling pathways. Inhibition of EGFR/HER2 by treatment with lapatinib blocked the AREG-induced activation of ERK1/2 and PI3K/AKT signaling pathways as well as AREGstimulated cell proliferation.

It is interesting to note that treatment with lapatinib did not affect proliferation of JEG-3 cells. It has been shown that the PI3K/AKT signaling pathway appears to be more dependent upon HER2 than EGFR signaling (23). Our results showed that the expression of HER2 was higher in BeWo cells than that in JEG-3 cells. In addition, compared to MEK inhibitor, treatment of cells with PI3K inhibitor induced a greater decrease in basal cell proliferation. Therefore, the low expression of HER2 and low activation of HER2-mediated PI3K/AKT signaling pathway in JEG-3 cells may be why lapatinib was unable to induce apoptosis in this cell line. The induction of apoptosis by lapatinib might, in part, be dependent upon the degree of HER2 expression and activation of the AKT signaling pathway.
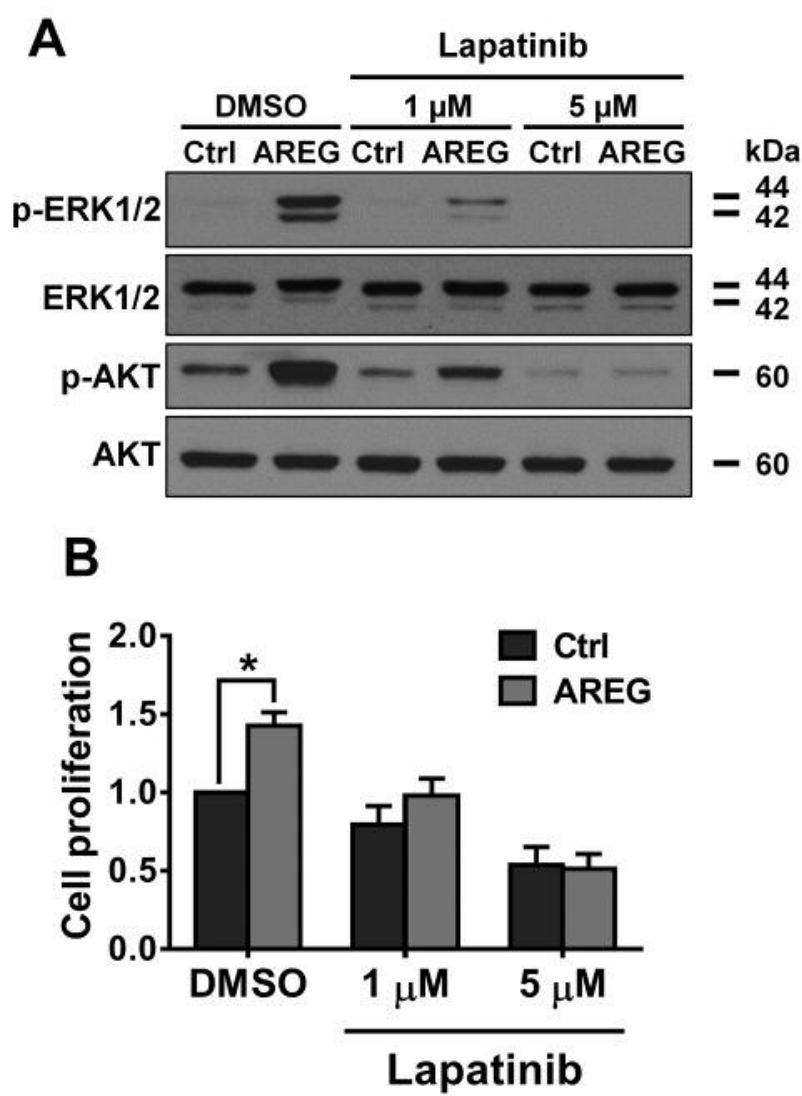

Figure 4. Lapatinib (Lap) blocks amphiregulin (AREG)-induced activations of extracellular signal-regulated kinases 1/2 (ERK1/2) and phosphatidylinositol 3-kinase/protein kinase B (PI3K/AKT) signaling pathways and AREG-stimulated cell proliferation in BeWo cells. A: Cells were pre-treated with 1 or $5 \mu \mathrm{M}$ lapatinib for $1 \mathrm{~h}$ and then treated with $20 \mathrm{ng} / \mathrm{ml}$ AREG for $60 \mathrm{~min}$. Phosphorylation of ERK1/2 and AKT was determined by western blot using antibodies specific for the phosphorylated forms of ERK1/2 (p-ERK1/2) and AKT (p-AKT). Membranes were stripped and reprobed with antibodies to total ERK1/2 and AKT. B: Cells were pre-treated with 1 or $5 \mu \mathrm{M}$ lapatinib for $1 \mathrm{~h}$ and then treated with $20 \mathrm{ng} / \mathrm{ml}$ AREG every $24 \mathrm{~h}$ for $96 \mathrm{~h}$. Cell proliferation was examined by the MTT assay. DMSO: Dimethyl sulfoxide. Cell proliferation results are presented as the mean \pm SEM of at least three independent experiments. *Significantly different at $p<0.05$ compared with the control (Ctrl).

EGFR signaling is known to regulate cell proliferation, motility, and invasion of many types of cancer $(24,25)$. EGFR is up-regulated in human gestational trophoblastic diseases including choriocarcinoma (12, 26, 27). Among EGFR ligands, AREG is the most highly expressed in amniotic fluid during human pregnancy. In addition, AREG treatment was found to stimulate human chorionic gonadotropin production in BeWo cells (17). Our study demonstrated that treatment with recombinant human AREG stimulated BeWo cell proliferation. 
Similarly to our previous studies on other cell types $(28,29)$, AREG treatment activated ERK1/2 and PI3K/AKT signaling pathways in human choriocarcinoma cells. We also reported that AREG-stimulated cell proliferation required the activation of ERK1/2 and PI3K/AKT signaling pathways. ERK1/2 is well known as a signaling pathway that regulates cancer cell proliferation and survival. In many types of human cancers, ERK1/2 signaling pathway has been found to be activated (30). The activation PI3K/AKT signaling pathway is involved in protecting cells from apoptosis. In cancer cells, constitutive activation of AKT signaling pathway has been implicated as a mechanism of resistance to cytotoxic chemotherapies (31). Our results showed that lapatinib blocked AREG-induced activation of ERK1/2 and PI3K/AKT signaling pathways in BeWo cells. These findings indicate that lapatinib acts as a potent EGFR/HER2 inhibitor, which can lead to cell growth arrest and apoptosis of human choriocarcinoma cells. Therefore, targeting EGFR might be a useful therapeutic strategy for the prevention of human choriocarcinoma development and progression

In summary, we demonstrated that treatment with lapatinib alone induced apoptosis of human choriocarcinoma cells with high HER2 expression. In addition, we showed the stimulatory effect of AREG on cell proliferation. Moreover, AREGstimulated cell proliferation was found to require the activation of ERK1/2 and PI3K/AKT signaling pathways. Furthermore, blocking EGFR/HER2 by lapatinib inhibited AREG-induced activation of ERK1/2 and PI3K/AKT signaling pathways as well as AREG-stimulated cell proliferation. The present study provides important insight into the molecular mechanisms mediating AREG-stimulated cell proliferation.

\section{Conflicts of Interests}

The Authors declare that they have no competing interests in regard to this study.

\section{Authors' Contributions}

LVC, JCC, PCKL and ISB conceived and designed the experiments; LVC, YY, LS and EC performed the experiments and analyzed the data; LVC, PCKL and ISB wrote the article. All Authors read and approved the final article.

\section{Acknowledgements}

This work was supported by a Foundation Grant from the Canadian Institutes of Health Research to P.C.K.L (FDN-143317).

\section{References}

1 Shih Ie M and Kurman RJ: Molecular basis of gestational trophoblastic diseases. Curr Mol Med 2(1): 1-12, 2002. PMID: 11898845

2 Shih IM and Kurman RJ: The pathology of intermediate trophoblastic tumors and tumor-like lesions. Int J Gynecol Pathol 20(1): 31-47, 2001. PMID: 11192071.
3 Seckl MJ, Sebire NJ, Fisher RA, Golfier F, Massuger L, Sessa $\mathrm{C}$ and Group EGW: Gestational trophoblastic disease: ESMO Clinical Practice Guidelines for diagnosis, treatment and followup. Ann Oncol 24(Suppl 6): vi39-50, 2013. PMID: 23999759. DOI: $10.1093 /$ annonc/mdt345

4 Shih Ie M: Gestational trophoblastic neoplasia - pathogenesis and potential therapeutic targets. Lancet Oncol 8(7): 642-650, 2007. PMID: 17613426. DOI: 10.1016/S1470-2045(07)70204-8

5 Ngan HY, Seckl MJ, Berkowitz RS, Xiang Y, Golfier F, Sekharan PK and Lurain JR: Update on the diagnosis and management of gestational trophoblastic disease. Int J Gynaecol Obstet 131(Suppl 2): S123-126, 2015. PMID: 26433668. DOI: 10.1016/j.ijgo.2015.06.008

6 Cagayan MS and Lu-Lasala LR: Management of gestational trophoblastic neoplasia with metastasis to the central nervous system: A 12-year review at the Philippine General Hospital. J Reprod Med 51(10): 785-792, 2006. PMID: 17086807.

7 Lurain JR, Singh DK and Schink JC: Primary treatment of metastatic high-risk gestational trophoblastic neoplasia with EMA-CO chemotherapy. J Reprod Med 51(10): 767-772, 2006. PMID: 17086804.

8 Newlands ES: The management of recurrent and drug-resistant gestational trophoblastic neoplasia (GTN). Best Pract Res Clin Obstet Gynaecol 17(6): 905-923, 2003. PMID: 14614889.

9 Ngan HY, Tam KF, Lam KW and Chan KK: Relapsed gestational trophoblastic neoplasia: A 20-year experience. J Reprod Med 51(10): 829-834, 2006. PMID: 17086812.

10 Berkowitz RS and Goldstein DP: Current management of gestational trophoblastic diseases. Gynecol Oncol 112(3): 654662, 2009. PMID: 18851873. DOI: 10.1016/j.ygyno.2008.09.005

11 Alazzam M, Tidy J, Hancock BW and Powers H: Gestational trophoblastic neoplasia, an ancient disease: new light and potential therapeutic targets. Anticancer Agents Med Chem 10(2): 176-185, 2010. PMID: 20015010.

12 Tuncer ZS, Vegh GL, Fulop V, Genest DR, Mok SC and Berkowitz RS: Expression of epidermal growth factor receptorrelated family products in gestational trophoblastic diseases and normal placenta and its relationship with development of postmolar tumor. Gynecol Oncol 77(3): 389-393, 2000. PMID: 10831347. DOI: $10.1006 /$ gyno.2000.5777

13 Yazaki-Sun S, Daher S, de Souza Ishigai MM, Alves MT, Mantovani TM and Mattar R: Correlation of c-ERB-2 oncogene and p53 tumor suppressor gene with malignant transformation of hydatidiform mole. J Obstet Gynaecol Res 32(3): 265-272, 2006. PMID: 16764615. DOI: 10.1111/j.1447-0756.2006.00397.x

14 Yang X, Zhang Z, Jia C, Li J, Yin L and Jiang S: The relationship between expression of c-Ras, c-ERBB-2, NM23, and p53 gene products and development of trophoblastic tumor and their predictive significance for the malignant transformation of complete hydatidiform mole. Gynecol Oncol 85(3): 438-444, 2002. PMID: 12051871.

15 Wang Z: ERBB receptors and cancer. Methods Mol Biol 1652: 335, 2017. PMID: 28791631. DOI: 10.1007/978-1-4939-7219-7_1

16 Hynes NE and MacDonald G: ERBB receptors and signaling pathways in cancer. Curr Opin Cell Biol 21(2): 177-184, 2009. PMID: 19208461.

17 Fukami T, Yoshizato T, Miyamoto S, Yagi H, Yotsumoto F, Nabeshima K, Hachisuga T, Kuroki M and Kawarabayashi T: Amphiregulin regulates the production of human chorionic gonadotropin in trophoblasts. Life Sci 84(23-24): 796-804, 2009. PMID: 19344731. DOI: 10.1016/j.lfs.2009.03.009 
18 Graus-Porta D, Beerli RR, Daly JM and Hynes NE: ERBB-2, the preferred heterodimerization partner of all ERBB receptors, is a mediator of lateral signaling. Embo J 16(7): 1647-1655, 1997. PMID: 9130710

19 Olayioye MA, Neve RM, Lane HA and Hynes NE: The ERBB signaling network: Receptor heterodimerization in development and cancer. Embo J 19(13): 3159-3167, 2000. PMID: 10880430.

20 Rusnak DW, Lackey K, Affleck K, Wood ER, Alligood KJ, Rhodes N, Keith BR, Murray DM, Knight WB, Mullin RJ and Gilmer TM: The effects of the novel, reversible epidermal growth factor receptor/ERBB-2 tyrosine kinase inhibitor, GW2016, on the growth of human normal and tumor-derived cell lines in vitro and in vivo. Mol Cancer Ther 1(2): 85-94, 2001. PMID: 12467226.

21 Wilken JA, Webster KT and Maihle NJ: Trastuzumab sensitizes ovarian cancer cells to EGFR-targeted therapeutics. J Ovarian Res 3: 7, 2010. PMID: 20346177. DOI: 10.1186/1757-2215-3-7

22 Cheng JC, Qiu X, Chang HM and Leung PC: HER2 mediates epidermal growth factor-induced down-regulation of E-cadherin in human ovarian cancer cells. Biochem Biophys Res Commun 434(1): 81-86, 2013. PMID: 23542467. DOI: 10.1016/j.bbrc.2013 03.062

23 Tari AM and Lopez-Berestein G: Serum predominantly activates MAPK and akt kinases in EGFR- and ERBB2-over-expressing cells, respectively. Int J Cancer 86(2): 295-297, 2000. PMID: 10738260 .

24 El-Rayes BF and LoRusso PM: Targeting the epidermal growth factor receptor. Br J Cancer 91(3): 418-424, 2004. PMID: 15238978

25 Marmor MD, Skaria KB and Yarden Y: Signal transduction and oncogenesis by ERBB/HER receptors. Int J Radiat Oncol Biol Phys 58(3): 903-913, 2004. PMID: 14967450.
26 Balaram P, John M, Rajalekshmy TN, Nair B, Schultz G and Nair K: Expression of epidermal growth factor receptor in gestational trophoblastic diseases. J Cancer Res Clin Oncol 123(3): 161-166, 1997. PMID: 9119881.

27 John M, Rajalekshmy T, Nair B, Augustine J, Schultz G, Nair K and Balaram P: Expression of epidermal growth factor and its receptor in gestational trophoblastic diseases. Oncol Rep 4(1): 177-182, 1997. PMID: 21590037.

28 So WK, Cheng JC, Liu Y, Xu C, Zhao J, Chang VT and Leung PC: SPROUTY4 mediates amphiregulin-induced downregulation of E-cadherin and cell invasion in human ovarian cancer cells. Tumour Biol 37(7): 9197-9207, 2016. PMID: 26768617. DOI: 10.1007/s13277-016-4790-y

29 Fang L, Cheng JC, Chang HM, Sun YP and Leung PC: EGFlike growth factors induce COX-2-derived PGE2 production through ERK1/2 in human granulosa cells. J Clin Endocrinol Metab 98(12): 4932-4941, 2013. PMID: 24092824. DOI: 10.1210/jc.2013-2662

30 Caunt CJ, Sale MJ, Smith PD and Cook SJ: MEK1 and MEK2 inhibitors and cancer therapy: the long and winding road. Nat Rev Cancer 15(10): 577-592, 2015. PMID: 26399658. DOI: $10.1038 / \mathrm{nrc} 4000$

31 Mayer IA and Arteaga CL: The PI3K/AKT pathway as a target for cancer treatment. Annu Rev Med 67: 11-28, 2016. PMID: 26473415. DOI: 10.1146/annurev-med-062913-051343

Received January 31, 2019

Revised April 10, 2019

Accepted April 11, 2019 